\title{
Retinoic acid synthesis and functions in early embryonic development
}

\author{
Richard Kin Ting Kam', Yi Deng ${ }^{2}$, Yonglong Chen ${ }^{3^{*}}$ and Hui Zhao ${ }^{1,4^{*}}$
}

\begin{abstract}
Retinoic acid (RA) is a morphogen derived from retinol (vitamin A) that plays important roles in cell growth, differentiation, and organogenesis. The production of RA from retinol requires two consecutive enzymatic reactions catalyzed by different sets of dehydrogenases. The retinol is first oxidized into retinal, which is then oxidized into RA. The RA interacts with retinoic acid receptor (RAR) and retinoic acid $X$ receptor (RXR) which then regulate the target gene expression. In this review, we have discussed the metabolism of RA and the important components of RA signaling pathway, and highlighted current understanding of the functions of RA during early embryonic development.
\end{abstract}

Keywords: retinoids, retinoic acid synthesis, embryonic development, organogenesis

\section{Introduction}

Retinoids refer to those chemicals that are structurally or functionally similar to retinol, or vitamin A [1], which is an essential biomolecule for embryonic development and adult body homeostasis. All retinoids retain the polyene hydrophobic tail attached to a cyclic 6-carbon ring. The polyene tail is characterized by the alternating conjugated carbon-carbon double bonds, which makes retinoids light-sensitive. In contrast with other signaling proteins, retinoids have a much lower molecular weight of approximately $300 \mathrm{Da}$. Given their molecular structures, retinoids are highly oil-soluble and able to diffuse across the cell membrane. Retinoids are involved in cellular growth, apoptosis, immune response, and epithelial growth [2-7] through the interaction with the nuclear receptors, retinoic acid receptor (RAR) and retinoid X receptor (RXR). During early embryonic development, the major active form of retinoids, all-trans retinoic acid (atRA), regulates germ layer formation, body axis formation, neurogenesis, cardiogenesis, and the development of pancreas, lung, and eye. It is also a critical element for visual function [8]. Because of the wide spectrum of RA functions, the metabolism,

\footnotetext{
* Correspondence: chen_yonglong@gibh.ac.cn; zhaohui@cuhk.edu.hk ${ }^{1}$ School of Biomedical Sciences, Faculty of Medicine, The Chinese University of Hong Kong, Shatin, New Territories, Hong Kong, P. R. China ${ }^{3}$ Center for Molecular Medicine, Guangzhou Institute of Biomedicine and Health, Chinese Academy of Sciences, Guangzhou, P. R. China Full list of author information is available at the end of the article
}

regulation, and function of vitamin A have been extensively studied for decades, and here we summarize our current understanding on retinoids metabolic pathways and RA functions during early embryonic development.

\section{Metabolism of vitamin A and the production of all-trans retinoic acid}

Vitamin A is a necessary dietary vitamin for the normal development and vision. The critical necessity of vitamin A was hinted as early as 1881 by Nikolai Lunin, who discovered that purified protein, fat, and carbohydrate did not sustain the normal growth of mice, unless the diet was supplemented with milk. Elmer Verner McCollum, then determined in 1917 that the critical component concerned in milk was actually a "fat-soluble factor A", named in contrast to the previously discovered "water-soluble factor B", or vitamin B. These discoveries allowed Carl Edvard Bloch, a Denmark paediatrician, to identify vitamin A deficiency as the cause of night blindness, or xerophthalmia [9].

While vitamin A was a necessary dietary vitamin, vitamin A itself is not the main bioactive mediator of its function. The key mediators of vitamin A function were identified as atRA and 11-cis retinal. atRA is a regulator of gene transcription, while 11-cis retinal acts as a chromophore for visual functions [10]. In this section, we will review the metabolic processes of converting vitamin A into various retinoids, with emphasis on the production of atRA (Figure 1).

\section{Biomed Central}




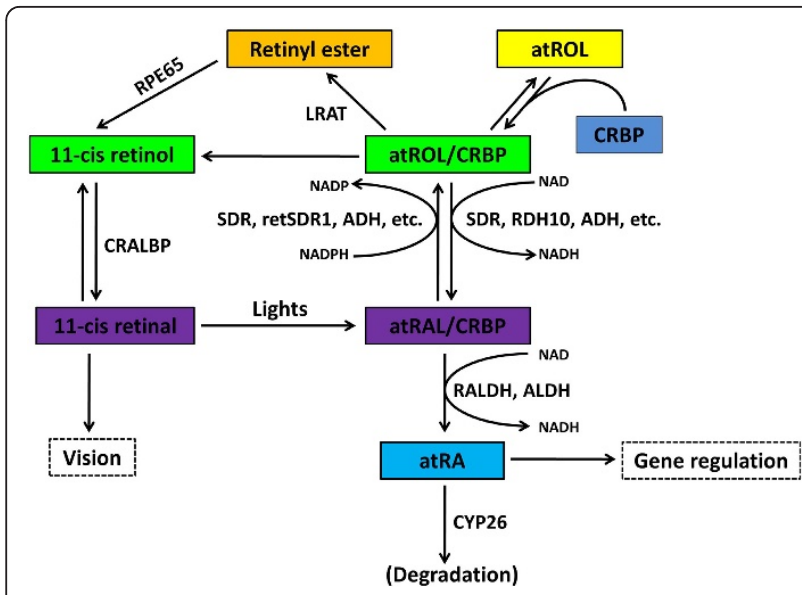

Figure 1 Schematic diagram showing the metabolic pathways of vitamin A metabolism. This illustration lists the major steps of RA metabolism in cell, please refer to the text for details. Abbreviation: NAD, nicotinamide adenine dinucleotide; NADH, The reduced form of NAD; NADP, nicotinamide adenine dinucleotide phosphate; NADPH, The reduced form of NADP; CRBP: cellular retinol-binding protein; LRAT: lecithin retinol acyltransferase; REH: retinyl ester hydrolase; $\mathrm{ADH}$ : alcohol dehydrogenase; $\mathrm{RDH}$ : retinol dehydrogenase; SDR: short-chain dehydrogenase/reductases; ALDH: aldehyde dehydrogenase; RALDH: retinaldehyde dehydrogenase. CRAD: cis-retinoid/androgen dehydrogenase. Modified from [18,25].

\subsection{Conversion of Vitamin A (atROL) to all-trans retinal (atRAL)}

Vitamin A (hereby referred to as all-trans retinol, atROL) is absorbed in the small intestine and esterified as retinyl esters for the blood stream transport. Retinyl ester is first transported to the liver for storage, mainly in the hepatic stellate cell. Hydrolysis of retinyl esters results in retinol, which then binds to retinol binding protein (RBP). The atROL/RBP complex is the dominant form for systematical and intercellular transport. After target organs take up the atROL/RBP complex, the atROL either is re-esterified into retinyl ester by lecithin retinol acyltransferase (LRAT) or binds to cellular retinol-binding protein (CRBP). The CRBP can prevent intracellular atROL from non-specific oxidation, immobilize intracellular retinol for storage, and acts as a carrier protein to present the atROL to respective retinol dehydrogenase for oxidation, or to LRAT for esterification [11]. Thus, the esterification by LRAT and/or the binding to CRBP represent the most upstream regulation of atROL availability, and therefore atRA metabolism, in the cell [12].

Retinyl ester and CRBP-bound retinol are the main storage forms of atROL. The retinyl ester can be hydrolyzed into 11-cis retinol by isomerohydrolases [13,14]. The cellular retinaldehyde binding protein (CRALBP) binds to 11-cis retinol with high affinity [15], which leads to the oxidation of 11-cis retinol to 11-cis retinal by 11 -cis retinol dehydrogenase $[16,17]$. The 11-cis retinal is an essential component for vision. It binds to opsin to form rhodopsin, which can absorb lights within the visible spectrum. When the 11-cis-retinal absorbs a photon, it isomerizes from the 11-cis state to atRAL. The binding of atRAL to opsin is not stable and atRAL is rapidly released from opsin. Such molecule movements cause cell membrane change, and eventually lead to generation of the nerve impulse for vision (Figure 1).

atROL/CRBP complexes are the first substrate in the metabolic pathway which leads to the production of atRA. Using atROL/CRBP as substrate, retinol dehydrogenase (RDH), which belongs to short-chain dehydrogenase/reductase (SDR) family, catalyzes the oxidation of atROL to all-trans retinal (atRAL) [18]. This step is the rate limiting step in the production of atRA [19]. It has also been demonstrated that in vitro free atROL can be converted into atRAL by non-specific enzymes including alcohol dehydrogenase [20]. CRBP therefore provides a selection mechanism for specific RDHmediated oxidation of atROL. Indeed, RDH has a much higher affinity towards atROL/CRBP complex than free atROL and the reaction depends on protein-protein interaction between RDH and CRBP [21]. It has been demonstrated that the microsomal RDH interacts with atROL/CRBP-I in the presence of co-factor, nicotinamide adenine dinucleotide phosphate (NADP) [22]. Moreover, atROL/CRBP is the preferred substrate for the retinol dehydrogenase 16 ( $\mathrm{RDH} 16$. Abbreviated as RoDH-4 in the original article), but not for $3 \alpha$-hydroxysteroid dehydrogenase ( $3 \alpha-$ HSD), a similar alcohol dehydrogenase which has an even higher affinity towards free atROL [23]. Thus, CRBP acts as a selection protein for RDH by increasing the substrate affinity for $\mathrm{RDH}$, which in turn prevents non-specific oxidation of atROL by alcohol dehydrogenase.

The conversion of atROL to atRAL is, in fact, reversible. The direction - oxidation or reduction - favored by different members of SDR family depends on the substrate affinity, co-factor affinity, and the rate of reaction. In addition to CRBP that contributes to substrate affinity, another factor that contributes to substrate affinity is the intrinsic substrate binding site on the SDR family of enzymes. Retinal reductase 1 (RalR1), a human SDR, has been shown to be reactive towards both atROL and atRAL in vitro. However, RalR1 has a higher affinity and rate of reduction for atRAL than atROL, indicating that RalR1 is a retinal reductase, rather than retinol dehydrogenase, under physiological conditions [24]. Co-factor affinity of different SDR has also been demonstrated that the co-factor favored by SDR reflects the direction of reaction catalyzed by that particular SDR (reviewed by Pares) [25].

Apart from RalR1, a number of retinal reductases have been identified in the past decades. A human short- 
chained retinol reductase (retSDR1) identified in a neuroblastoma cell line has been shown to promote the formation of retinyl ester in the presence of exogenous atRAL [26]. A mouse liver peroxisomal SDR termed mouse retinal reductase (RRD) also showed a high atRAL-specific reductase activity in the presence of CRBP in vitro [27]. This enzyme was induced by peroxisome proliferator-activated receptor (PPAR), suggesting a relationship between retinoid metabolism and peroxisome activity [27]. Using in vitro assay, some studies have identified reductases which showed in vitro retinalreducing activity. For example, human aldose reductase and human small intestine aldose reductase can function as retinal reductase in vitro [28]. Similarly, the mouse short-chained aldehyde reductase (SCALD) could reduce atRAL and 9-cis retinal in vitro [29]. However, these studies are based on in vitro biochemical analysis only and do not take into account the substrate selection by CRBP. Therefore, the enzymatic activities on different retinal reported should not be taken as a direct evidence for physiological retinal reductases.

\subsection{Conversion of atRAL to atRA}

Similar to atROL, all-trans retinal is also transported by CRBP in the cell, and is then oxidized to atRA. The oxidation from atRAL to atRA has been observed as early as 1960 [30]. The oxidation of atRAL to atRA was mediated by various retinaldehyde dehydrogenases (RALDH). At least 3 RALDHs have been identified in human, mouse, and Xenopus, with different physiological functions [31]. Retinaldehyde dehydrogenase 1 (Raldh1) is highly expressed in the dorsal retina of mouse embryos [32], in epithelial tissues of adult mice and Xenopus [33], and in the stomach and small intestine of adult rats [34]. Xenopus raldh1 has been shown to be an atRA synthesizing enzyme in a retinoic acid responsive cell line [35]. RALDH1 $1^{-/}$mice also suggest that Raldh1 is capable of atRA synthesis [36]. However, knockout of RALDH1 did not severely affect the morphology of the retina although RALDH1 is localized in the dorsal retina [36], indicating that other enzymes might redundantly share the function of RALDH1.

The retinaldehyde dehydrogenase 2 (RALDH2) was identified in human, mouse, chick, zebrafish and Xenopus [37-39]. Interestingly, RALDH2 was identified as a crucial enzyme for atRA synthesis in different organisms. Knockout of $R A L D H 2$ was embryonic lethal during the postimplantation period in mice [40], suggesting that atRA is essential for normal embryonic development. The phenotypes of RALDH2 knock-out mice include severely impaired segmentation of rhombomeres, altered homeobox gene expression pattern, and defective neural crest cell migration [41]. In zebrafish, knockdown of raldh2 caused a down-regulation of retinoic acid signaling, malformation in the central nervous system, and disruption of left-right asymmetry $[42,43]$. The raldh 2 mutant, neckless (nls), displayed a suppressed formation of the midbrain to hindbrain region, as well as segmentation defects in rhombomeres [44]. Such defects were attributed to the reduction in atRA signaling [45], since the spatial and temporal pattern of atRA signaling is maintained mainly by raldh 2 and a degradative enzyme cytochrome P450 hydroxylase A1 (cyp26a1) in zebrafish. In Xenopus embryos, ectopic expression of raldh 2 caused teratogenic effects such as the expression of posterior neural markers (en2 and krox20) in the anterior region, which is similar to that due to atRA toxicity [38], suggesting that raldh2 is an important enzyme in maintaining atRA homeostasis in embryos. Knockdown of raldh2 in Xenopus embryos caused a shortening of anteroposterior axis and a posterior shift of neural marker en 2 and krox20 [46]. Collectively, such evidence indicated that raldh2 plays a crucial role in the anteroposterior patterning of the central nervous system and trunk axis through regulation of the RA signaling.

Retinaldehyde dehydrogenase 3 (RALDH3) has been identified in human, chick, mouse, zebrafish, and Xenopus, and is expressed in the ventral retina across various species [47-51]. Studies in mouse have shown that RALDH3 was mainly involved in the frontonasal development and patterning of ocular structures [52]. Mice lacking $R A L D H 3$ were neonatal lethal, due to the respiratory tract obstruction in nasal region, and the neonatal lethality could be rescued by atRA supplements [53], suggesting that RALDH3 is an atRA synthesis enzyme. In 2007, Halilagic et al. showed that atRA production by RALDH3 contributed to the correct patterning of the anterior and dorsal boundaries of the developing forebrain [54]. It was further delineated that RALDH3 knockout mice exhibited loss of dopamine receptor D2 in the ventral forebrain. These studies suggest that RALDH3 is essential for the development of the central nervous system and the morphogenesis of anterior head structures [52].

Similar to atROL and atRAL, the metabolism of atRA is also closely related to retinoid binding protein termed cellular retinoic acid binding proteins (CRABPs). CRABPs bind to intracellular RA and prevent it from non-specific degradation $[55,56]$. There are two species of CRABP, CRABP-I and CRABP-II. These carrier proteins also ensure the solubility of hydrophobic retinoid in the aqueous intracellular environment. However, a recent study of CRBP-I/CRABP-I/CRABP-II triple knock-out mice has shown that the main regulator of retinoid homeostasis was likely to be CRBPs, with CRABPs playing a minor role in this process. Hoegberg et al. found that the chemical-induced depletion of total retinoids in triple knockout mice was more severe than the wild type and CRABP-I/CRABP-II double knockout 
mice [57], suggesting that CRBP-I is a more potent regulator of retinoid homeostasis. While CRABPs might not be critical in regulating total retinoids homeostasis, they participate in mediating RA signaling by transporting RA to the nucleus to interact with RARs. CRABP-II was shown to be translocated into nucleus upon the ligand binding [58], which allows atRA to bind to and activate RAR, a transcription factor responsible for the RA signaling (Figure 2). Interestingly, the RA signaling is tightly regulated by negative feedback mechanisms as CRABP-II is negatively regulated by atRA [59]. Elevated RA signaling suppresses the production of CRABPs, which down-regulate the activation of RARs and the RA signaling. CRABP-I, on the other hand, regulates the rate of RA metabolism by presenting RA to the degrading enzyme CYP26A1 [60].

\subsection{Degradation of atRA}

All-trans retinoic acid is degraded by CYP26 enzymes, which belong to cytochrome P450 hydroxylase family. A number of CYP26 family including CYP26A1, B1, C1, and D1 have been characterized and all of them possess the ability to degrade atRA into less bio-active retinoid [61-63]. Rhombomeric alteration defects were only observed by the knockdown of all three cyp26 enzymes in zebrafish [64], suggesting that cyp26a1, b1 and c1 act redundantly in hindbrain patterning. CYP26A1 is induced by atRA while it promotes the hydroxylation of atRA into 4-hydroxy retinoic acid, 4-oxo retinoic acid, and 18-hyroxy retinoic acid [45,65-67]. Since RALDH2 and CYP26A1 are both regulated by atRA itself, the metabolism of atRA therefore forms an auto-regulatory loop that regulates and balances atRA levels in embryos. Such regulation not only maintains the endogenous atRA level within a normal range, but also allows the organisms to respond to exogenous atRA fluctuation.

\section{Retinoic acid receptors}

atRA is carried into the nucleus by CRABP-II, and interacts with RARs, which themselves are transcription

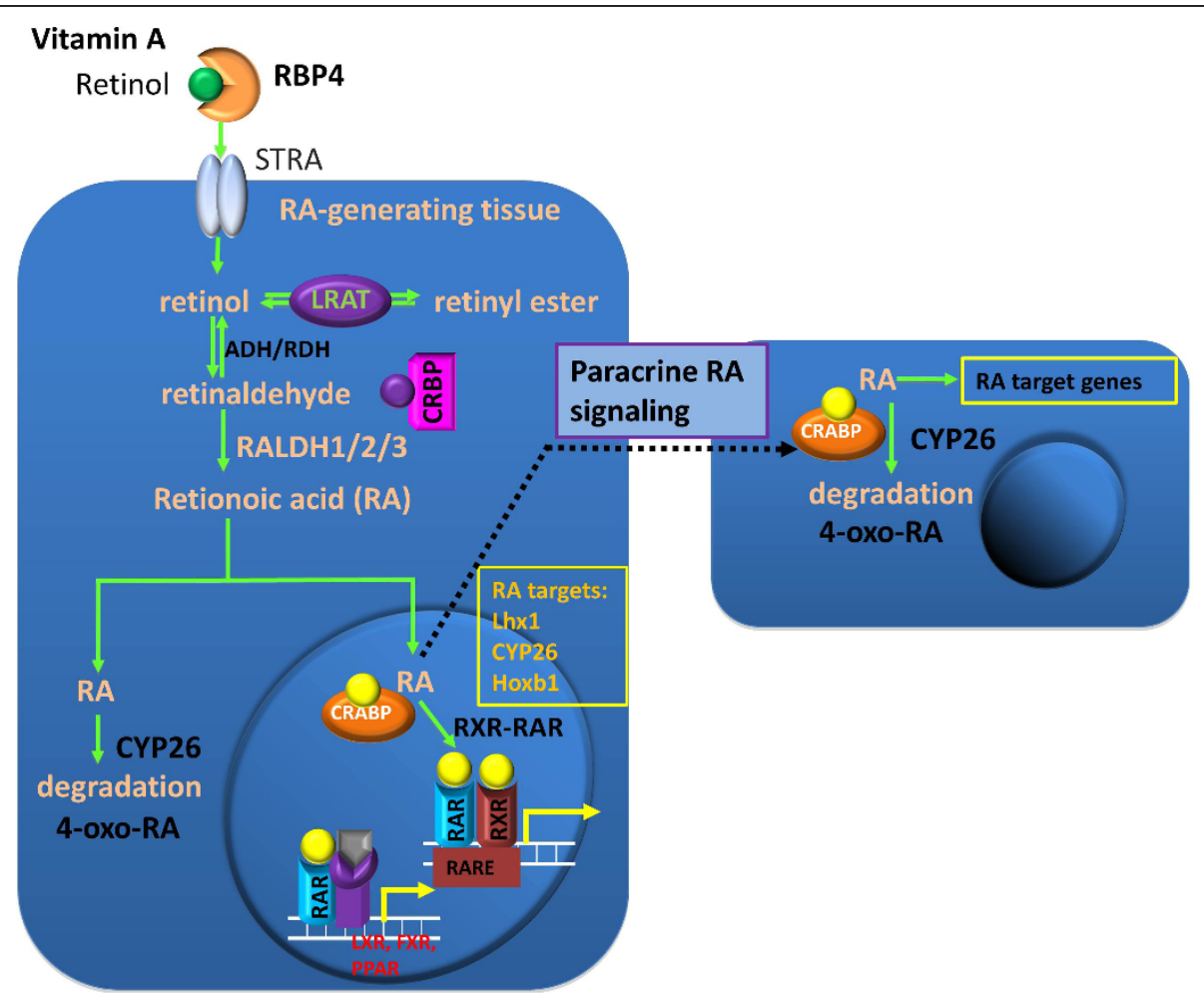

Figure 2 Ilustration of RA and paracrine RA signaling. In serum, retinol is bound to retinol-binding protein 4 (RBP-4) synthesized in the liver. Although retinol is lipid soluble, it enters cells mainly through the interaction with its receptor STRA. In the cell, retinol can either be converted into retinyl esters for storage via lecithin retinol acyltransferase (LRAT) or bind to the cellular retinol binding protein (CRBP). The CRBP-bound retinol is oxidized to retinal by either alcohol dehydrogenase (ADH) or retinol dehydrogenase (RDH), and retinal is oxidized to retinoic acid (RA) by retinaldehyde dehydrogenases (RALDH1/2/3). All-trans retinoic acid (atRA) is the major bioactive component among the retinoids. CYP26 can further oxidize atRA to 4-oxo-RA for degradation. Cellular retinoic acid-binding protein (CRABP) facilitates transportation of atRA into the nucleus where atRA binds its receptors. The ternary complex of ligand-bound RAR and RXR binds to the retinoic acid response element (RARE) and activates the RA target genes. atRA can diffuse to adjacent cells to activate target gene expression in these cells. RAR can also bind to the liver $X$ receptor (LXR), farnesoid X receptor (FXR), and peroxisome proliferator-activated receptor (PPAR) for multiple functions. 
factors. RARs belong to retinoid receptor family, which also includes another group called retinoid $\mathrm{X}$ receptors (RXRs). RARs recognize both atRA and 9-cis retinoic acid, while RXRs only recognize 9-cis retinoic acid. Upon the ligand binding, RAR dimerizes with RXR to form a heterodimer, which then initiate gene transcription by binding to the retinoic acid response element (RARE) in the promoter region of the targets genes (Figure 2). The RAR family consists of RAR $\alpha / \beta / \gamma$ three members that bind to atRA [68-71]. Single knockout mice that lack each of RARs were not embryonic lethal and did not display the complete spectrum of vitamin A deficiency phenotype. A disruption in RAR $\alpha$ did not cause any observable phenotypic change in a mouse model [72]. Knockout of RAR $\beta$ caused a reduction in the body weight and ocular defect, while limb formation remained normal [73]. Double knockout of two RAR $\gamma$ subtypes caused growth deficiency, cartilage dysmorphogenesis, and vertebrate malformation [74]. These results imply that RARs work redundantly and compensate the function of each other. Indeed, knockdown of RAR $\alpha$ caused an increase in the expression level of RAR $\beta$ and RAR $\gamma$ [75]. Only double knockout mutants showed phenotype close to the symptoms of vitamin A deficiency [76]. The auto-regulatory loop of $R A R$ expression is similar to that regulating the expression of of RALDH2 and CYP26a1. Moreover, RARE has been identified in the promoter regions of $R A R \alpha$ and $\beta$ [77-79], indicating that the expression of these RARs is also under control of atRA.

Similarly, there are also three subtypes of RXRs [80]. RXR $\alpha$ knockout mice were embryonic lethal, potentially due to malformation of the heart in utero [81]. RXR $\beta$ knockout mice were $50 \%$ embryonic lethal, and the surviving littermates were morphologically normal except spermatogenesis defects which rendered the male sterile [82], while the RXR $\gamma$-null mutant mice were morphologically normal when compared with the wild type [83]. Moreover, the mice carrying only one copy of RXR $\alpha$ (RXR $\alpha+/-/ R X R \beta-/-/ R X R \gamma-/-)$ were viable, suggesting one copy of RXR $\alpha$ is sufficient to carry out most of function of the RXRs [83]. Since atRA-bound RAR can form heterodimer with RXR in the absence of 9-cis retinoic acid and is still active in transcription activities, the importance of RXRs may not be as critical as RARs. This may explain why only one copy of RXR $\alpha$ is sufficient for the mouse embryonic development. Taken together, these results suggest that each of the RAR subtypes function redundantly and most of the RXR subtypes are not critical for the embryonic development.

While RARs mainly mediate the RA signaling, it has been revealed by many studies that ligand-bound RXRs activate other signaling pathways by forming heterodimer with other nuclear receptors such as liver $\mathrm{X}$ receptor (LXR), farnesoid X receptor (FXR), and PPAR [84-86] (Figure 2). LXR mainly functions as a sensor of cholesterol levels by recognizing its ligand oxysterols. Overloading cells with cholesterol activates LXR/RXR heterodimers which in turn initiate transcription of target genes, thereby regulate cholesterol transport, uptake, metabolism, and bile acid synthesis in the liver $[87,88]$. FXR can recognize free or conjugated bile acid and thus acts as an intracellular sensor of bile acid to regulate the metabolism of bile acid in the liver. Activation of liganded-FXR/RXR promotes bile acid efflux and inhibits bile acid synthesis [89]. PPAR is a lipid sensing nuclear receptor, recognizing a wide range of fatty acids [90]. These interactions between LXR, FXR, PPAR, and RXR reflect the complexity of RXR functions and their potentials on the RA signaling. In addition, not only do RXRs take part promiscuously in multiple signaling pathways, the expression of these nuclear receptors is also under control of complex feedback loops and crosstalks with other signaling pathways [91]. The heterodimerization of RXR with RAR, LXR, FXR, or PPAR is therefore mutually competitive, and atRA signaling not only triggers the transcription of its target genes, but also competitively suppresses the transcription of others. This may explain the board spectrum of atRA-induced teratogenicity observed in embryos.

\section{Differential expression and gene regulation of RA metabolic enzymes}

The RA metabolic enzymes show distinct differential expression pattern during early embryonic development, and interestingly their expression is regulated by the RA signaling. Detailed descriptions of the expression patterns of these genes are beyond the scope of this review. Schematic drawing of expression of rdh10, dhrs3, raldh2, cyp26a1, raro2, and crabp-II at Xenopus gastrula (stage 11) and neurula (stage 14) stages are illustrated in Figure 3, which shows that the RA signaling itself regulates expression of the enzymes for RA biosynthesis and elicits the complexity of RA acting as a morphogen in early embryonic development. Ectopic cyp26 expression can be induced by atRA treatment [92], while the embryos treated with atRA showed down-regulation of raldh2 [38] and rdh10 [46]. Dhrs3 can also be induced by atRA treatment (RKT Kam, Y Chen, WY Chan and $\mathrm{H}$ Zhao. Dhrs3 attenuates the retinoic acid signaling and is required for early embryonic patterning. Submitted). Thus the RA signaling down-regulates the expression of the enzymes for atRA production, but upregulates enzymes that can reduce atRA level in embryos. Other components in the RA signaling are also responsive to atRA treatment. For example, crabpII was found to be an atRA-inducible gene [93], and was found to contain a RARE domain in its promoter region 


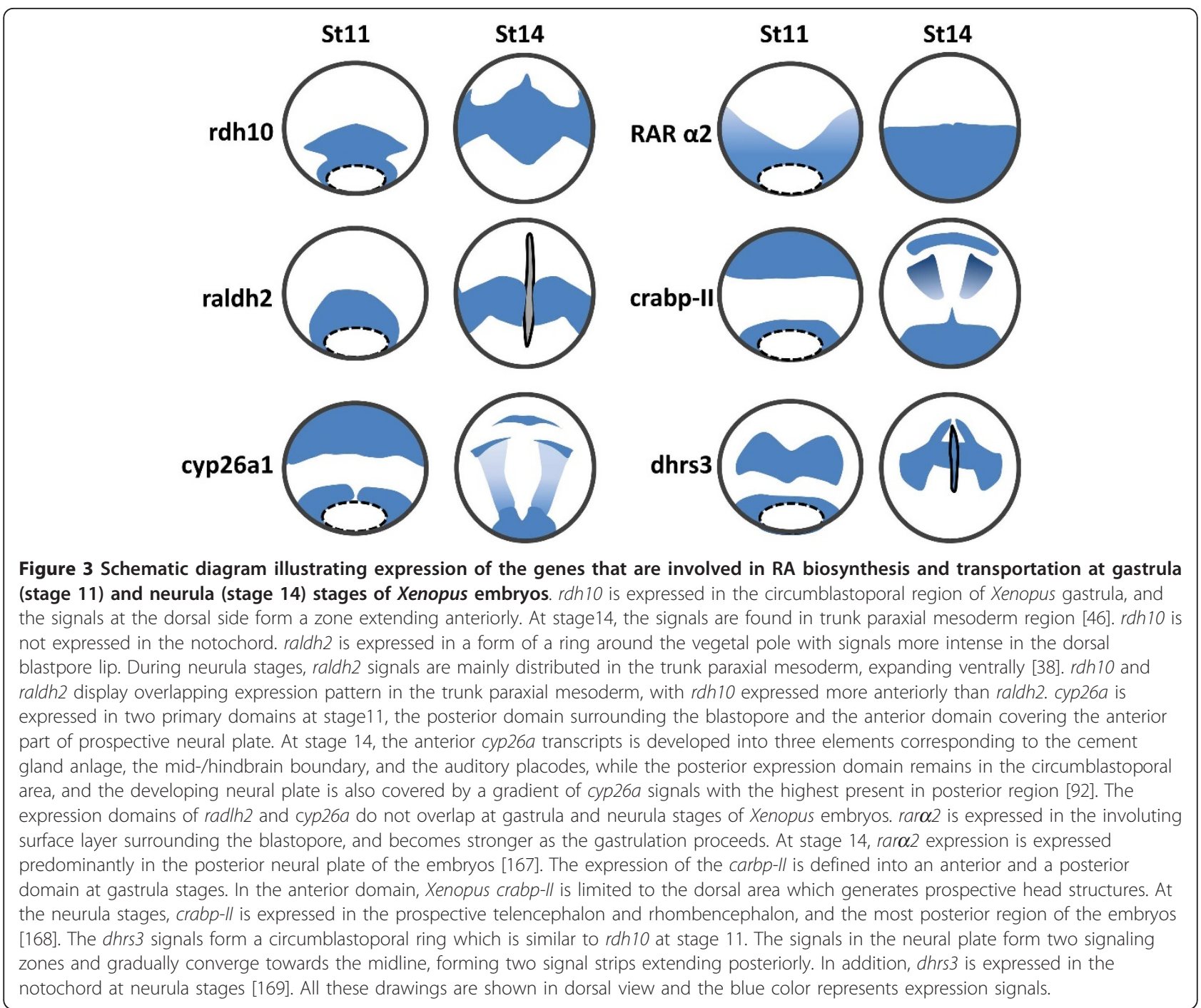

[94]. Similarly, raro2 was found to be inducible by atRA treatment in leukemic cell lines [95], and in rat embryos as well [96]. We summarize the regulation of these genes by RA signaling in Figure 4.

\section{Retinoic acid signaling during early embryonic development}

The RA signaling pathway has been implicated in various developmental processes. During early embryonic development, retinoids act as an important morphogen across different species from invertebrate to metazoan including human $[97,98]$. It participates in regulating various biological processes, such as apoptosis and differentiation, and cell fate specification.

\subsection{Axis formation}

The RA signaling has been implicated in embryonic axis formation as well. Evidence shows that it interacts with

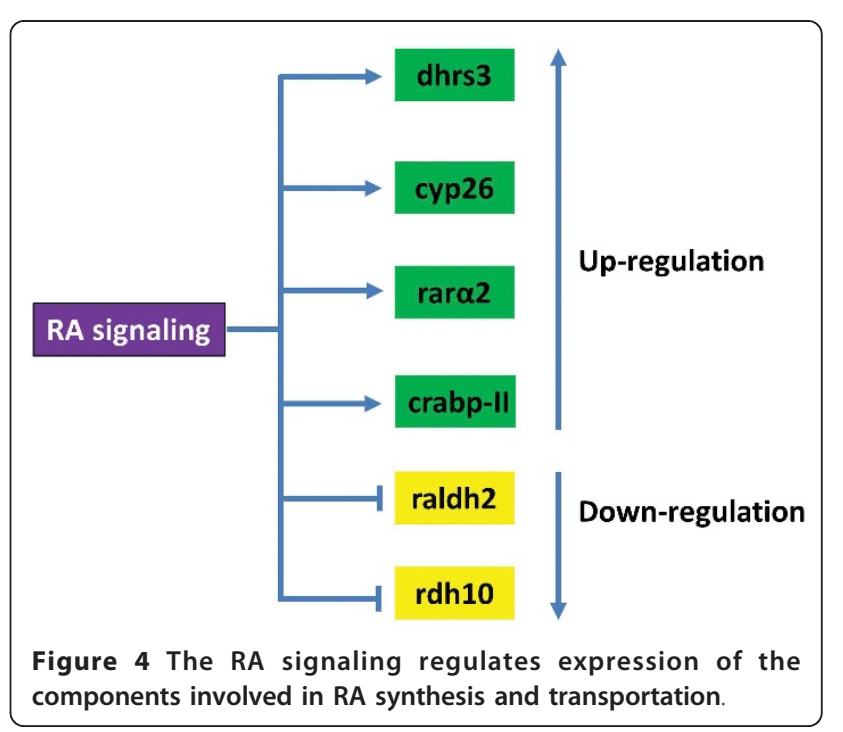


Nodal signaling to regulate dorsoventral axis formation. The mice embryos lacking all three Cyp26 genes displayed secondary body axes due to expansion of the Nodal expression domain. In fact, the mouse Nodal gene contains an RARE in the intron 1 that is highly conserved among mammals [99]. Moreover, pre-gastrulation mouse embryos express Cyp26s but not Raldhs suggesting that maternal RA is decreased by embryonic Cyp26s for proper Nodal expression during embryonic patterning [99].

In addition to the dorsoventral axis formation, cyp 26 is also important for restricting the expression of posterior genes during the anteroposterior patterning [100]. Experiments in zebrafish embryos indicate that reduction of atRA by ectopic cyp26 decreased the expression of posterior genes meis3. Consistent with this, knockdown of cyp26 led to the anterior expansion of meis3. Interestingly, the expression of cyp 26 is suppressed by the FGF and Wnt signalings, which are involved in the specification of posterior trunk during the gastrulation. Thus, RA together with FGF and Wnt signalings forms a complex regulatory network to regulate the anteroposterior axis formation in gastrula embryos, the cyp26 being one of the cross-talk genes linking these signaling pathways [100].

The RALDHs and CYP26s enzymes also participate in the anteroposterior patterning of the central nervous system by maintaining a gradient of atRA along the axis [101]. Global application of atRA to mouse embryos during day 7 of gestation caused severe head deformations, such as exencephaly, microcephaly, and anencephaly, whereas exposure of embryos to atRA during day 8 of gestation led to severe caudal truncations reminiscent of the human caudal regression syndrome $[102,103]$. Similar phenomena were observed with Xenopus embryos as well [104-106].

Vertebrates display asymmetric placement of various internal organs including the heart, liver, spleen, and gut, and the asymmetric development of paired organs such as brain hemispheres and lungs. Treatment with RA antagonist in mouse led to randomization of heart looping and perturbed sideness of node [107]. Application of RA antagonist revealed that the RA signaling sequentially controlled visceral and heart laterality [108]. On the other hand, the somites obviously avoid the influence of signaling pathways that regulate the leftright asymmetry. The somites, derived from the trunk paraxial mesoderm and sequentially segmented along the anteroposterior axis, are formed as bilaterally paired units. However, the mice embryos that lack Raldh 2 exhibited asymmetric somite formation [109], which was due to left-right desynchronization of the segmentation clock oscillations. Such defects were also observed in RA deficient chick [110] and zebrafish [43]. It is therefore postulated that the RA form a protection zone, protecting the somite from the left-right asymmetric signals to maintain the bilateral symmetry of somites columns.

\subsection{Neural differentiation}

atRA has been known for its ability to induce neural differentiation. During neural differentiation in early embryonic development, the pro-neural induction factor Neurogenin 2 (Neurog2) is required for primary sensory neuron specification [111]. Two RARE identified in the promoter region of mouse Neurog 2 provide evidence that atRA directly regulates the expression of Neurog2 and therefore neural differentiation [112]. In addition, it has been shown that atRA treatment can induce pluripotent embryonic carcinoma stem cell line NT2 cells to differentiate into forebrain, hindbrain, and spinal cord neural progenitors [113], and the NT2 cells displayed GABAergic and glutamatergic phenotype. In line with this, mouse embryonic stem cells could be induced into GABAergic neurons by atRA treatment in vitro [114]. These in vitro findings were also supported by an in vivo study that knockdown of $R A R \alpha$ abolished the effect of atRA on dendritic growth [115]. Collectively, these studies support the view that atRA is required for neural differentiation in the central nervous system.

\subsection{Hindbrain patterning}

Vertebrate hindbrain contains seven rhombomeres. Several Hox genes have been shown to be involved in rhombomeres formation and/or provide positional identity to specific rhombomeres [116]. Two RAREs have been identified in Hoxb1, one of which is located 5 ' to Hoxb1 promoter and is required for the restricted expression in rhombomere 4 [117]. Studies in mouse and fish embryos showed that retinoids could induce ectopic expression of Hoxal and Hoxb1, which caused a rhombomere 2 to 4 transformation [118-120]. In addition, the Hnflb that suppressed Hoxbl expression in rhombomere 5 was also regulated by the RA signaling $[121,122]$. Altogether, these data implicate that the RA signaling is involved in hindbrain patterning. Indeed, knockout mice lacking Raldh2 led to the conversion of caudal hindbrain segments into rhombomere 4 identity $[123,124]$ and the same is true for RA antagonist treated mice [109]. In chick embryos, treatment by using increasing concentrations of RA antagonist, BMS453, showed that successively more posterior rhombomere boundaries required progressively higher concentration of endogenous retinoic acid for their correct positioning [125]. In zebrafish embryos, rhombomere 5 of the caudal hindbrain is well specified but both rhombomere 4 and 5 were posteriorly expanded in the absence of RA $[42,126]$. In Xenopus embryos, injection of cyp $26 a 1$ 
mRNAs into one side of the embryo resulted in alterations of the RA signaling at the injected side as indicated by posteriorization of krox 20 , a transcription factor marking the rhombomere 3 and 5 [92], whereas increasing the RA signaling via ectopic expression of raldh 2 led to anteriorization of both midbrain and hindbrain rhombomere identities in the expense of some forebrain territory [38] (Figure 5). Despite this, studies in mouse and Xenopus showed that decreased RA signaling did not change the mid-/hindbrain boundary (MHB) [41,92], which requires the orchestration of a complex regulatory network involving the FGF, Wnt, and Shh signalings [127]. On the contrary, the hindbrain/spinal cord boundary seems to be specified depending on the RA signaling. In zebrafish cyp26a1 mutant embryos, the expression domains of hoxb5a and $h o x b 6 a$ were expanded rostrally, leading to the expansion of rostral spinal cord at the expense of the hindbrain territory [128].

\subsection{Pancreas}

The RA signaling also plays essential roles in the regionalization of endoderm as early as during gastrulation [129]. Studies in frog, avian, and mice indicate that the RA signaling is essential for dorsal pancreas formation, partially required for ventral pancreas patterning [129-134]. In zebrafish, inhibition of RA signaling before the end of gastrulation inhibits the initial development of both hepatic and pancreatic endoderm [135]. Evidence shows that it is the RA signal emanating from paraxial mesoderm that directly induces endocrine

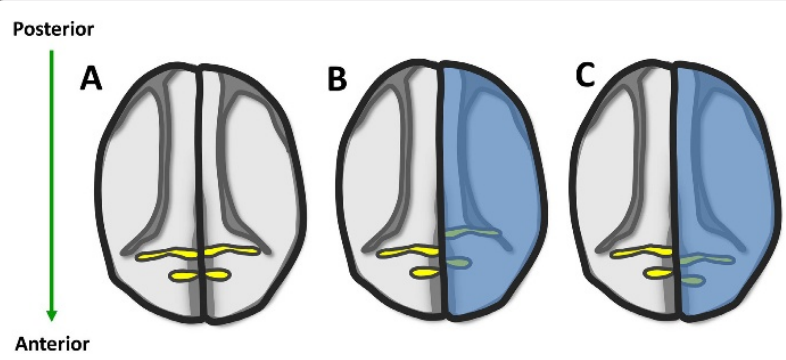

Figure 5 Schematic diagram of krox20 expression in control embryos $(A)$, and in embryos with alterated $R A$ signaling $(B, C)$. Alternation of RA gradient induces shift of the expression domain of krox20. The expression of krox20 labels rhombomeres 3 and 5 ( $A$, yellow). Co-injection of lacZ and cyp26 or rdh10 or rdh2 mRNA into one blastomere of two-cell stage Xenopus embryos is indicated by LacZ staining ( $B, C$, blue). The uninjected side is served as control. Ectopic cyp26 at one side of the embryos causes posterior shift of krox20 (B, yellow). In contrast to cyp26, overexpression of rdh10 and radlh2 leads to anterior shift of krox20 (C, yellow). This diagram is based on the previous reports and our unpublished data $[46,92,129]$ (RKT Kam, Y Chen, WY Chan and H Zhao. Dhrs3 attenuates the retinoic acid signaling and is required for early embryonic patterning. Submitted.)

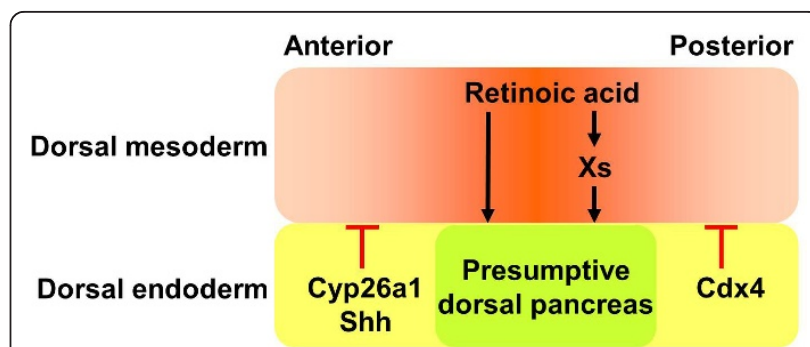

Figure 6 RA plays an essential role in dorsal pancreas specification. During gastrulation and early neurulation, the field in dorsal endoderm that gives rise to the presumptive dorsal pancreas is just underlying the dorsal mesoderm where the highest concentration of RA is generated. These RA signals can act to underly endoderm either directly, or indirectly via first activating unknown factors (Xs) in mesoderm, which then act on the endoderm for dorsal pancreas formation. As described in the text, Shh and Cyp26al expressed in more anterior dorsal endoderm block pancreas formation probably via inhibiting the RA signaling activity or directly degrading RA. C $d x 4$ expressed in the posterior dorsal endoderm helps to establish the posterior boundary of dorsal pancreas via antagonizing the RA signaling.

pancreatic precursors in the adjacent endoderm [136]. For example, $M n x 1$ is identified as an RA downstream gene that controls cell fate choice in the developing endocrine pancreas [137]. Cyp26a1, expressed in endoderm, defines the anterior boundary of dorsal pancreatic anlage by inactivating excess RA [138], while $C d x 4$, expressed in posterior endoderm, acts to antagonize the RA signaling and thus establishes the posterior boundary of dorsal pancreatic territory in zebrafish embryos (Figure 6; [139]). Moreover, Raldh1 is expressed in developing mouse and human pancreas at stages when mature $\beta$-cells are generated [140], suggesting the role of RA in $\beta$-cell differentiation. The XPDIp is expressed in the exocrine portion of both dorsal and ventral pancreas. Inhibition of RA signaling by BMS453 treatment completely abolished expression of XPDIp in dorsal pancreas, but had mild effects on the ventral pancreas, suggesting the development of dorsal pancreas is more RA signaling dependent [129].

In addition, in vitro data have also demonstrated a role of RA in pancreas development. In a defined in vitro explant system, RA treatment of cultured mouse E10.5 dorsal pancreatic buds could induce the generation of $\mathrm{Ngn3}+$ endocrine progenitor cells and stimulate their further differentiation into $\beta$-cells by activating a differentiation program that recapitulates the normal temporal program of $\beta$-cell differentiation [140]. In zebrafish, exogenous RA led to expansion of both exo- and endocrine cells, while in Xenopus embryos as well as cultured mouse embryonic pancreatic rudiments, exogenous RA led to an expansion of the endocrine cell population at the expense of the exocrine cells in the 
dorsal pancreas $[129,141,142]$. Similarly, the induction of pancreatic fate by RA in endodermalized naive ectoderm dissected from early Xenopus gastrulae only showed the generation of early insulin-expressing cells [143,144]. Therefore, cautions should be taken to apply RA at the right time and the right dose (close to physiological concentration in early embryos) for in vitro induction of mature pancreatic $\beta$-cells from embryonic stem cells.

\subsection{Heart}

The effect of RA on cardiogenesis was first demonstrated in quail that vitamin A deficiency could induce defective primitive heart development [145]. Further evidence shows that RA signaling is required for the formation of cardiac progenitors [146], and the correct modeling of the early heart field and the anteroposterior patterning of the heart is controlled by atRA through the action of Isl1 and Fgf8 signaling pathway [147,148]. Knockout mice embryos lacking Raldh2 showed an abnormal development of the second heart field (SHF) [149], which is a population of undifferentiated cardiac precursor cells originating from the pharyngeal mesoderm and lying medial to the cardiac crescent (the first heart field). The expression of SHF markers including Isl1, $T b x 1$, and $F g f 8$, was posteriorly expanded in these embryos [150], indicating that the RA signaling is required for the restriction of SHF. Defects in the formation of a proper heart tube might also partially explain why Raldh2-/- is embryonic lethal [148]. Studies in zebrafish indicated RA functions in the restriction of cardiac specification [149]. During this process, if RA signaling was inhibited in lateral mesoderm, the uncommitted cells could differentiate into myocardial progenitor cells instead of pharyngeal or pancreatic cells [149], leading to the expansion of cardiomyocytes.

In addition to the heart development, the RA signaling has also been implicated in heart regeneration in adult zebrafish. Gene profiling assay indicated that raldh2 was one of the most highly induced genes in the regenerating heart [151]. After the ventricular injury, raldh2 was activated in the endocardium, but its expression was subsequently restricted in endocardial cells at the injury site one day post-trauma as the repairing cardiogenesis began. By 7 days after amputation, the epicardial cells at the injury site also expressed raldh2. Inhibition of RARs or expression of an RA-degrading enzyme blocked regenerative cardiomyocyte proliferation [152]. These findings reveal essential roles of RA in repairing the damaged heart tissue and promoting cardiomyocyte proliferation.

\subsection{Kidney}

There is increasing evidence indicating that atRA plays important roles in kidney development [153-155]. The kidney field is derived from the intermediate mesoderm. The specification of renal progenitor cells is influenced by RA signals emanating from the paraxial mesoderm [153-155]. Recent studies in Xenopus and zebrafish have demonstrated that ectopic production of RA increased the size of the kidney field, while blocking the pathway inhibited the kidney specification [86,154]. In Xenopus, pax 8 and $\operatorname{lh} x 1$, which are the earliest determinants of pronephric fate are both under control of the RA signaling $[154,156]$, while pteg, an early pronephric marker, is a direct target of the RA signaling and an essential factor for pronephric specification [157]. Another critical factor for the pronephros development, Wilm's tumor suppressor (wt1), is under direct control of the RA signaling as well $[158,159]$. Inhibition of RA by BMS453 treatment caused reduction of pronephros field, as revealed by the decreased expression of the pronephros markers including smp-30 and pax2 at the late tailbud stage [154]. Furthermore, in Xenopus embryos, the pluripotent animal cap cells treated with RA and activin could differentiate into pronephros tissue [154,160]. Likewise, the RA signaling is also essential for directing the proximodistal patterning of pronephric nephron in zebrafish [161]. The exogenous RA could induce proximal segment fates at the expense of distal fates, whereas inhibition of the RA signaling caused a loss of the proximal segments and an expansion of the distal segments.

Interestingly, inactivation of both $R A R \alpha$ and $R A R \beta$ in mice embryos resulted in renal malformations [155]. Further evidence showed that $R A R \alpha$ and $R A R \beta$ were coexpressed with Ret, a receptor tyrosine kinase involved in renal development, in renal stromal mesenchyme, where their deletion led to altered stromal cell patterning, impaired ureteric bud growth, and down-regulation of Ret in the ureteric bud. Moreover, studies in mice indicate that the RA signaling in ureteric bud cells mainly depends on atRA generated through Raldh2 in stromal cells [162].

\subsection{Lung}

Evidence indicates that disruption of the RA signaling during early development caused abnormalities of lung formation. Either knockout of Raldh2 or treatment with BMS 493, a RA inhibitor, caused defects of lung formation in mice [163]. During primary lung bud morphogenesis, although RA is not required for specification of lung cell fate in the endoderm, it is essential for the induction of the primordial lung buds [163,164]. During the induction of lung bud, the RA signaling inhibits the expression of $D k k-1$, the Wnt signaling inhibitor, in the foregut mesoderm. This inhibition in turn activates Wnt signaling in the lung bud region. At the same time, the RA signaling also inhibits TGF- $\beta$ signaling. The balanced Wnt and TGF- $\beta$ signalings coordinate with 
each other to induce and maintain the optimal expression level of Fgf1O for the induction of the lung primordium [165]. Furthermore, airway branching was accompanied by down-regulation of the RA signaling pathway [166], thus regional mechanisms that control RA availability and utilization are important for the lung morphogenesis.

\section{Concluding remarks}

To date, it has been demonstrated that the RA signaling plays sophisticated roles in early embryonic development. In fact, gastrulation is a very critical period for the RA signaling to exert its function in the regionalization of all three germ layers along the anteroposterior axis. RA is mainly generated in the mesoderm and thus can be most efficiently used. It is not clear as to how the RA metabolic enzymes coordinate with each other to generate the RA gradient at right time, right region, and with right strength during early embryonic development. Future studies are needed to identify the immediate and direct RA target genes in distinct RA responsive cells and to define the crosstalks between RA and other signaling pathways, such as hedgehog, FGF, Wnt, and Notch signalings for the formation and regionalization of three germ layers. Such knowledge will be essential for understanding organogenesis and establishing reliable strategies for stem cell differentiation into specific cell types that can be used for treatment of human diseases.

\begin{abstract}
Acknowledgements
We thank members of our laboratories for valuable discussion. This work is supported by GRF grant from the Research Grants Council of Hong Kong (No. CUHK480709) to HZ, the National Basic Research Program of China (2009CB941202), and the fund from the Key Project of Knowledge Innovation Program of the Chinese Academy of Sciences (KSCX2-YW-R-083) to YLC. RKTK was supported by the Graduate Studentships from The Chinese University of Hong Kong.

\section{Author details \\ ${ }^{1}$ School of Biomedical Sciences, Faculty of Medicine, The Chinese University of Hong Kong, Shatin, New Territories, Hong Kong, P. R. China. ${ }^{2}$ Department of Medicine and Therapeutics, Faculty of Medicine, The Chinese University of Hong Kong, Shatin, New Territories, Hong Kong, P. R. China. ${ }^{3}$ Center for Molecular Medicine, Guangzhou Institute of Biomedicine and Health, Chinese Academy of Sciences, Guangzhou, P. R. China. ${ }^{4}$ Key Laboratory for Regenerative Medicine, Ministry of Education, Ji Nan University-The Chinese University of Hong Kong, Shatin, New Territories, Hong Kong, P. R. China.}

\section{Authors' contributions}

RKTK and $\mathrm{HZ}$ planned the manuscript outline. RKTK, $\mathrm{HZ}$ and $\mathrm{YLC}$ wrote the draft, YD revised and did proof reading, $H Z$ and YLC finalized the manuscript. All authors read and approve the final manuscript.

\section{Competing interests}

The authors declare that they have no competing interests.

Received: 2 December 2011 Accepted: 22 March 2012

Published: 22 March 2012
References

1. Tang XH, Gudas LJ: Retinoids, retinoic acid receptors, and cancer. Annu Rev Pathol 2011, 6:345-364

2. Duriancik DM, Lackey $D E$, Hoag KA: Vitamin $A$ as a regulator of antigen presenting cells. J Nutr 140(8):1395-1399.

3. Gudas $L J$, Wagner JA: Retinoids regulate stem cell differentiation. J Cell Physio/ 226(2):322-330.

4. Hogarth CA, Griswold MD: The key role of vitamin A in spermatogenesis. J Clin Invest 120(4):956-962.

5. Mora JR, Iwata M, von Andrian UH: Vitamin effects on the immune system: vitamins A and D take centre stage. Nat Rev Immunol 2008, 8(9):685-698

6. Mukherjee S, Date A, Patravale V, Korting HC, Roeder A, Weindl G: Retinoids in the treatment of skin aging: an overview of clinical efficacy and safety. Clin Interv Aging 2006, 1(4):327-348.

7. Pino-Lagos K, Benson MJ, Noelle RJ: Retinoic acid in the immune system. Ann N Y Acad Sci 2008, 1143:170-187.

8. Davies WL, Hankins MW, Foster RG: Vertebrate ancient opsin and melanopsin: divergent irradiance detectors. Photochem Photobiol Sci 2010, 9(11):1444-1457.

9. Wolf G: The discovery of the visual function of vitamin A. J Nutr 2001 131(6):1647-1650.

10. D'Ambrosio DN, Clugston RD, Blaner WS: Vitamin A Metabolism: An Update. 2011, 3(1):63-103.

11. Penzes $P$, Napoli JL: Holo-cellular retinol-binding protein: distinction of ligand-binding affinity from efficiency as substrate in retinal biosynthesis. Biochemistry 1999, 38(7):2088-2093.

12. Liu L, Gudas LJ: Disruption of the lecithin:retinol acyltransferase gene makes mice more susceptible to vitamin A deficiency. J Biol Chem 2005, 280(48):40226-40234

13. Deigner PS, Law WC, Canada FJ, Rando RR: Membranes as the energy source in the endergonic transformation of vitamin A to 11-cis-retinol. Science 1989, 244(4907):968-971.

14. Mata NL, Moghrabi WN, Lee JS, Bui TV, Radu RA, Horwitz J, Travis GH: Rpe65 is a retinyl ester binding protein that presents insoluble substrate to the isomerase in retinal pigment epithelial cells. J Biol Chem 2004, 279(1):635-643.

15. Saari JC, Nawrot M, Kennedy BN, Garwin GG, Hurley JB, Huang J, Possin DE, Crabb JW: Visual cycle impairment in cellular retinaldehyde binding protein (CRALBP) knockout mice results in delayed dark adaptation. Neuron 2001, 29(3):739-748.

16. Driessen $C A$, Janssen $B P$, Winkens $H J$, van Vugt $A H$, de Leeuw $T L$, Janssen JJ: Cloning and expression of a CDNA encoding bovine retinal pigment epithelial 11-cis retinol dehydrogenase. Invest Ophthalmol Vis Sci 1995, 36(10):1988-1996.

17. Simon A, Hellman U, Wernstedt C, Eriksson U: The retinal pigment epithelial-specific 11-cis retinol dehydrogenase belongs to the family of short chain alcohol dehydrogenases. J Biol Chem 1995, 270(3):1107-1112.

18. Duester $\mathrm{G}$ : Families of retinoid dehydrogenases regulating vitamin $\mathrm{A}$ function: production of visual pigment and retinoic acid. Eur J Biochem 2000, 267(14):4315-4324

19. Agadir A, Nau H, Blaner WS: Retinoids: the biochemical and molecular basis of Vitamin A and retinoid action. Berlin; New York Springer; 1999.

20. Posch KC, Enright WJ, Napoli JL: Retinoic acid synthesis by cytosol from the alcohol dehydrogenase negative deermouse. Arch Biochem Biophys 1989, 274(1):171-178.

21. Noy N: Retinoid-binding proteins: mediators of retinoid action. Biochem $J$ 2000, 348(Pt 3):481-495.

22. Boerman $\mathrm{MH}$, Napoli JL: Characterization of a microsomal retinol dehydrogenase: a short-chain alcohol dehydrogenase with integral and peripheral membrane forms that interacts with holo-CRBP (type I). Biochemistry 1995, 34(21):7027-7037.

23. Lapshina EA, Belyaeva OV, Chumakova OV, Kedishvili NY: Differential recognition of the free versus bound retinol by human microsomal retinol/sterol dehydrogenases: characterization of the holo-CRBP dehydrogenase activity of RoDH-4. Biochemistry 2003, 42(3):776-784.

24. Belyaeva OV, Stetsenko AV, Nelson P, Kedishvili NY: Properties of shortchain dehydrogenase/reductase RalR1: characterization of purified enzyme, its orientation in the microsomal membrane, and distribution in human tissues and cell lines. Biochemistry 2003, 42(50):14838-14845. 
25. Pares X, Farres J, Kedishvili N, Duester G: Medium- and short-chain dehydrogenase/reductase gene and protein families: Medium-chain and short-chain dehydrogenases/reductases in retinoid metabolism. Cell Mol Life Sci 2008, 65(24):3936-3949.

26. Cerignoli F, Guo X, Cardinali B, Rinaldi C, Casaletto J, Frati L, Screpanti I, Gudas LJ, Gulino A, Thiele CJ, et al: retSDR1, a short-chain retinol dehydrogenase/reductase, is retinoic acid-inducible and frequently deleted in human neuroblastoma cell lines. Cancer Res 2002, 62(4):1196-1204

27. Lei Z, Chen W, Zhang M, Napoli JL: Reduction of all-trans-retinal in the mouse liver peroxisome fraction by the short-chain dehydrogenase/ reductase RRD: induction by the PPAR alpha ligand clofibrate. Biochemistry 2003, 42(14):4190-4196.

28. Crosas B, Hyndman DJ, Gallego O, Martras S, Pares X, Flynn TG, Farres J: Human aldose reductase and human small intestine aldose reductase are efficient retinal reductases: consequences for retinoid metabolism. Biochem J 2003, 373(Pt 3):973-979.

29. Kasus-Jacobi A, Ou J, Bashmakov YK, Shelton JM, Richardson JA, Goldstein $\lrcorner$, Brown MS: Characterization of mouse short-chain aldehyde reductase (SCALD), an enzyme regulated by sterol regulatory elementbinding proteins. J Biol Chem 2003, 278(34):32380-32389.

30. Dowling JE, Wald G: The role of vitamin A acid. Vitam Horm 1960, 18:515-541.

31. Duester G, Mic FA, Molotkov A: Cytosolic retinoid dehydrogenases govern ubiquitous metabolism of retinol to retinaldehyde followed by tissuespecific metabolism to retinoic acid. Chem Biol Interact 2003, 143144:201-210.

32. Haselbeck RJ, Hoffmann I, Duester G: Distinct functions for Aldh1 and Raldh2 in the control of ligand production for embryonic retinoid signaling pathways. Dev Genet 1999, 25(4):353-364.

33. Ang HL, Duester G: Retinoic acid biosynthetic enzyme ALDH1 localizes in a subset of retinoid-dependent tissues during xenopus development. Dev Dyn 1999, 215(3):264-272.

34. Frota-Ruchon A, Marcinkiewicz M, Bhat PV: Localization of retinal dehydrogenase type 1 in the stomach and intestine. Cell Tissue Res 2000, 302(3):397-400.

35. Ang HL, Duester G: Stimulation of premature retinoic acid synthesis in Xenopus embryos following premature expression of aldehyde dehydrogenase ALDH1. Eur J Biochem 1999, 260(1):227-234.

36. Fan X, Molotkov A, Manabe S, Donmoyer CM, Deltour L, Foglio MH, Cuenca AE, Blaner WS, Lipton SA, Duester G: Targeted disruption of Aldh1a1 (Raldh1) provides evidence for a complex mechanism of retinoic acid synthesis in the developing retina. Mol Cell Biol 2003, 23(13):4637-4648.

37. Blentic A, Gale E, Maden M: Retinoic acid signalling centres in the avian embryo identified by sites of expression of synthesising and catabolising enzymes. Dev Dyn 2003, 227(1):114-127.

38. Chen $Y$, Pollet $N$, Niehrs $C$, Pieler T: Increased XRALDH2 activity has a posteriorizing effect on the central nervous system of Xenopus embryos. Mech Dev 2001, 101(1-2):91-103.

39. Niederreither K, McCaffery P, Drager UC, Chambon P, Dolle P: Restricted expression and retinoic acid-induced downregulation of the retinaldehyde dehydrogenase type 2 (RALDH-2) gene during mouse development. Mech Dev 1997, 62(1):67-78.

40. Niederreither K, Subbarayan V, Dolle P, Chambon P: Embryonic retinoic acid synthesis is essential for early mouse post-implantation development. Nat Genet 1999, 21(4):444-448.

41. Niederreither K, Vermot J, Schuhbaur B, Chambon P, Dolle P: Retinoic acid synthesis and hindbrain patterning in the mouse embryo. Development 2000, 127(1):75-85.

42. Grandel H, Lun K, Rauch GJ, Rhinn M, Piotrowski T, Houart C, Sordino P, Kuchler AM, Schulte-Merker S, Geisler R, et al: Retinoic acid signalling in the zebrafish embryo is necessary during pre-segmentation stages to pattern the anterior-posterior axis of the CNS and to induce a pectoral fin bud. Development 2002, 129(12):2851-2865.

43. Kawakami Y, Raya A, Raya RM, Rodriguez-Esteban C, Belmonte JC: Retinoic acid signalling links left-right asymmetric patterning and bilaterally symmetric somitogenesis in the zebrafish embryo. Nature 2005, 435(7039):165-171.

44. Begemann G, Marx M, Mebus K, Meyer A, Bastmeyer M: Beyond the neckless phenotype: influence of reduced retinoic acid signaling on motor neuron development in the zebrafish hindbrain. Dev Biol 2004, 271(1):119-129.

45. Dobbs-McAuliffe B, Zhao Q, Linney E: Feedback mechanisms regulate retinoic acid production and degradation in the zebrafish embryo. Mech Dev 2004, 121(4):339-350.

46. Strate I, Min TH, Iliev D, Pera EM: Retinol dehydrogenase 10 is a feedback regulator of retinoic acid signalling during axis formation and patterning of the central nervous system. Development 2009, 136(3):461-472.

47. Koenig SF, Brentle S, Hamdi K, Fichtner D, Wedlich D, Gradl D: En2, Pax2/5 and Tcf-4 transcription factors cooperate in patterning the Xenopus brain. Dev Bio/ 340(2):318-328.

48. Lupo G, Liu Y, Qiu R, Chandraratna RA, Barsacchi G, He RQ, Harris WA: Dorsoventral patterning of the Xenopus eye: a collaboration of Retinoid, Hedgehog and FGF receptor signaling. Development 2005, 132(7):1737-1748.

49. Mic FA, Molotkov A, Fan X, Cuenca AE, Duester G: RALDH3, a retinaldehyde dehydrogenase that generates retinoic acid, is expressed in the ventral retina, otic vesicle and olfactory pit during mouse development. Mech Dev 2000, 97(1-2):227-230.

50. Pittlik S, Domingues S, Meyer A, Begemann G: Expression of zebrafish aldh1a3 (raldh3) and absence of aldh1a1 in teleosts. Gene Expr Patterns 2008, 8(3):141-147.

51. Suzuki R, Shintani T, Sakuta H, Kato A, Ohkawara T, Osumi N, Noda M: Identification of RALDH-3, a novel retinaldehyde dehydrogenase, expressed in the ventral region of the retina. Mech Dev 2000, 98(12):37-50.

52. Molotkova N, Molotkov A, Duester G: Role of retinoic acid during forebrain development begins late when Raldh3 generates retinoic acid in the ventral subventricular zone. Dev Biol 2007, 303(2):601-610.

53. Dupe V, Matt N, Garnier JM, Chambon P, Mark M, Ghyselinck NB: A newborn lethal defect due to inactivation of retinaldehyde dehydrogenase type 3 is prevented by maternal retinoic acid treatment. Proc Natl Acad Sci USA 2003, 100(24):14036-14041.

54. Halilagic A, Ribes V, Ghyselinck NB, Zile MH, Dolle P, Studer M: Retinoids control anterior and dorsal properties in the developing forebrain. Dev Biol 2007, 303(1):362-375.

55. Chytil F, Ong DE: Cellular retinol- and retinoic acid-binding proteins in vitamin A action. Fed Proc 1979, 38(11):2510-2514.

56. Napoli $J$, Boerman MH, Chai X, Zhai Y, Fiorella PD: Enzymes and binding proteins affecting retinoic acid concentrations. J Steroid Biochem Mol Biol 1995, 53(1-6):497-502.

57. Hoegberg P, Schmidt CK, Fletcher N, Nilsson CB, Trossvik C, Gerlienke Schuur A, Brouwer A, Nau H, Ghyselinck NB, Chambon P, et al: Retinoid status and responsiveness to 2,3,7,8-tetrachlorodibenzo-p-dioxin (TCDD) in mice lacking retinoid binding protein or retinoid receptor forms. Chem Biol Interact 2005, 156(1):25-39.

58. Sessler RJ, Noy N: A ligand-activated nuclear localization signal in cellular retinoic acid binding protein-II. Mol Cell 2005, 18(3):343-353.

59. Stachurska E, Loboda A, Niderla-Bielinska J, Szperl M, Juszynski M, Jozkowicz A, Dulak J, Ratajska A: Expression of cellular retinoic acidbinding protein I and II (CRABP I and II) in embryonic mouse hearts treated with retinoic acid. Acta Biochim Pol 58(1):19-29.

60. Boylan JF, Gudas L: The level of CRABP-I expression influences the amounts and types of all-trans-retinoic acid metabolites in F9 teratocarcinoma stem cells. J Biol Chem 1992, 267(30):21486-21491.

61. Gu X, Xu F, Wang X, Gao X, Zhao Q: Molecular cloning and expression of a novel CYP26 gene (cyp26d1) during zebrafish early development. Gene Expr Patterns 2005, 5(6):733-739.

62. Sakai Y, Luo T, McCaffery P, Hamada H, Drager UC: CYP26A1 and CYP26C1 cooperate in degrading retinoic acid within the equatorial retina during later eye development. Dev Biol 2004, 276(1):143-157.

63. Takeuchi H, Yokota A, Ohoka Y, Iwata M: Cyp26b1 regulates retinoic aciddependent signals in $\mathrm{T}$ cells and its expression is inhibited by transforming growth factor-beta. PLoS One 6(1):e16089.

64. Hernandez RE, Putzke AP, Myers JP, Margaretha L, Moens CB: Cyp26 enzymes generate the retinoic acid response pattern necessary for hindbrain development. Development 2007, 134(1):177-187.

65. White JA, Beckett-Jones B, Guo YD, Dilworth FJ, Bonasoro J, Jones G, Petkovich M: cDNA cloning of human retinoic acid-metabolizing enzyme (hP450RAl) identifies a novel family of cytochromes P450. J Biol Chem 1997, 272(30):18538-18541 
66. de Roos K, Sonneveld E, Compaan B, ten Berge D, Durston AJ, van der Saag PT: Expression of retinoic acid 4-hydroxylase (CYP26) during mouse and Xenopus laevis embryogenesis. Mech Dev 1999, 82(1-2):205-211.

67. Swindell EC, Thaller C, Sockanathan S, Petkovich M, Jessell TM, Eichele G: Complementary domains of retinoic acid production and degradation in the early chick embryo. Dev Biol 1999, 216(1):282-296.

68. Giguere V, Ong ES, Segui P, Evans RM: Identification of a receptor for the morphogen retinoic acid. Nature 1987, 330(6149):624-629.

69. Petkovich M, Brand NJ, Krust A, Chambon P: A human retinoic acid receptor which belongs to the family of nuclear receptors. Nature 1987, 330(6147):444-450.

70. Brand N, Petkovich M, Krust A, Chambon P, de The H, Marchio A, Tiollais P, Dejean $A$ : Identification of a second human retinoic acid receptor. Nature 1988, 332(6167):850-853

71. Ruberte E, Dolle P, Krust A, Zelent A, Morriss-Kay G, Chambon P: Specific spatial and temporal distribution of retinoic acid receptor gamma transcripts during mouse embryogenesis. Development 1990, 108(2):213-222.

72. Li E, Sucov HM, Lee KF, Evans RM, Jaenisch R: Normal development and growth of mice carrying a targeted disruption of the alpha 1 retinoic acid receptor gene. Proc Natl Acad Sci USA 1993, 90(4):1590-1594.

73. Ghyselinck NB, Dupe V, Dierich A, Messaddeq N, Garnier JM, RochetteEgly C, Chambon P, Mark M: Role of the retinoic acid receptor beta (RARbeta) during mouse development. Int J Dev Biol 1997, 41(3):425-447.

74. Subbarayan V, Kastner P, Mark M, Dierich A, Gorry P, Chambon P: Limited specificity and large overlap of the functions of the mouse RAR gamma 1 and RAR gamma 2 isoforms. Mech Dev 1997, 66(1-2):131-142.

75. Manshouri T, Yang Y, Lin H, Stass SA, Glassman AB, Keating MJ, Albitar M: Downregulation of RAR alpha in mice by antisense transgene leads to a compensatory increase in RAR beta and RAR gamma and development of lymphoma. Blood 1997, 89(7):2507-2515.

76. Mark M, Ghyselinck NB, Wendling O, Dupe V, Mascrez B, Kastner P, Chambon $P$ : A genetic dissection of the retinoid signalling pathway in the mouse. Proc Nutr Soc 1999, 58(3):609-613.

77. Chomienne C, Balitrand N, Ballerini P, Castaigne S, de The H, Degos L: Alltrans retinoic acid modulates the retinoic acid receptor-alpha in promyelocytic cells. J Clin Invest 1991, 88(6):2150-2154.

78. Kamei $Y$, Kawada T, Kazuki R, Sugimoto E: Retinoic acid receptor gamma 2 gene expression is up-regulated by retinoic acid in 3T3-L1 preadipocytes. Biochem J 1993, 293(Pt 3):807-812.

79. Sucov HM, Murakami KK, Evans RM: Characterization of an autoregulated response element in the mouse retinoic acid receptor type beta gene. Proc Natl Acad Sci USA 1990, 87(14):5392-5396.

80. Chawla A, Repa JJ, Evans RM, Mangelsdorf DJ: Nuclear receptors and lipid physiology: opening the X-files. Science 2001, 294(5548):1866-1870.

81. Kastner P, Messaddeq N, Mark M, Wendling O, Grondona JM, Ward S, Ghyselinck N, Chambon P: Vitamin A deficiency and mutations of RXRalpha, RXRbeta and RARalpha lead to early differentiation of embryonic ventricular cardiomyocytes. Development 1997, 124(23):4749-4758

82. Kastner P, Mark M, Leid M, Gansmuller A, Chin W, Grondona JM, Decimo D, Krezel W, Dierich A, Chambon P: Abnormal spermatogenesis in RXR beta mutant mice. Genes Dev 1996, 10(1):80-92.

83. Krezel W, Dupe V, Mark M, Dierich A, Kastner P, Chambon P: RXR gamma null mice are apparently normal and compound RXR alpha +/-/RXR beta -/-/RXR gamma -/- mutant mice are viable. Proc Natl Acad Sci USA 1996, 93(17):9010-9014.

84. Mello T, Polvani S, Galli A: Peroxisome proliferator-activated receptor and retinoic x receptor in alcoholic liver disease. PPAR Res 2009, 2009:748174.

85. Rizzo G, Renga B, Antonelli E, Passeri D, Pellicciari R, Fiorucci S: The methyl transferase PRMT1 functions as co-activator of farnesoid $X$ receptor (FXR)/9-cis retinoid $X$ receptor and regulates transcription of FXR responsive genes. Mol Pharmacol 2005, 68(2):551-558.

86. Wingert RA, Davidson AJ: The zebrafish pronephros: a model to study nephron segmentation. Kidney Int 2008, 73(10):1120-1127.

87. Lagu B, Pio B, Lebedev R, Yang M, Pelton PD: RXR-LXR heterodimer modulators for the potential treatment of dyslipidemia. Bioorg Med Chem Lett 2007, 17(12):3497-3503.

88. Zhao C, Dahlman-Wright K: Liver $\mathrm{X}$ receptor in cholesterol metabolism. J Endocrinol 204(3):233-240
89. Desvergne B: RXR: from partnership to leadership in metabolic regulations. Vitam Horm 2007, 75:1-32.

90. Desvergne $B$, Wahli W: Peroxisome proliferator-activated receptors: nuclear control of metabolism. Endocr Rev 1999, 20(5):649-688.

91. Desvergne $B$, Michalik $L$, Wahli W: Transcriptional regulation of metabolism. Physiol Rev 2006, 86(2):465-514.

92. Hollemann T, Chen Y, Grunz H, Pieler T: Regionalized metabolic activity establishes boundaries of retinoic acid signalling. EMBO J 1998, 17(24):7361-7372.

93. Astrom A, Pettersson U, Voorhees JJ: Structure of the human cellular retinoic acid-binding protein II gene. Early transcriptional regulation by retinoic acid. J Biol Chem 1992, 267(35):25251-25255.

94. Durand B, Saunders M, Leroy P, Leid M, Chambon P: All-trans and 9-cis retinoic acid induction of CRABPII transcription is mediated by RAR-RXR heterodimers bound to DR1 and DR2 repeated motifs. Cell 1992, 71(1):73-85.

95. Zhu J, Heyworth CM, Glasow A, Huang QH, Petrie K, Lanotte M, Benoit G, Gallagher R, Waxman S, Enver T, et al: Lineage restriction of the RARalpha gene expression in myeloid differentiation. Blood 2001, 98(8):2563-2567.

96. Takeyama K, Kojima R, Ohashi R, Sato T, Mano H, Masushige S, Kato S: Retinoic acid differentially up-regulates the gene expression of retinoic acid receptor alpha and gamma isoforms in embryo and adult rats. Biochem Biophys Res Commun 1996, 222(2):395-400.

97. Halme A, Cheng M, Hariharan IK: Retinoids regulate a developmental checkpoint for tissue regeneration in Drosophila. Curr Biol 20(5):458-463.

98. Maden M: Retinoids in nonmammalian embryos. Methods Mol Biol 2008, 461:541-559.

99. Uehara M, Yashiro K, Takaoka K, Yamamoto M, Hamada H: Removal of maternal retinoic acid by embryonic CYP26 is required for correct Nodal expression during early embryonic patterning. Genes Dev 2009, 23(14):1689-1698.

100. Kudoh T, Wilson SW, Dawid IB: Distinct roles for Fgf, Wnt and retinoic acid in posteriorizing the neural ectoderm. Development 2002, 129(18):4335-4346.

101. White RJ, Schilling TF: How degrading: Cyp26s in hindbrain development. Dev Dyn 2008, 237(10):2775-2790

102. Kessel M, Gruss P: Homeotic transformations of murine vertebrae and concomitant alteration of Hox codes induced by retinoic acid. Cell 1991, 67(1):89-104.

103. Padmanabhan R: Retinoic acid-induced caudal regression syndrome in the mouse fetus. Reprod Toxicol 1998, 12(2):139-151.

104. Durston AJ, Timmermans JP, Hage WJ, Hendriks HF, de Vries NJ, Heideveld M, Nieuwkoop PD: Retinoic acid causes an anteroposterior transformation in the developing central nervous system. Nature 1989, 340(6229):140-144

105. Sive $\mathrm{HL}$, Draper BW, Harland RM, Weintraub $\mathrm{H}$ : Identification of a retinoic acid-sensitive period during primary axis formation in Xenopus laevis. Genes Dev 1990, 4(6):932-942.

106. Ruiz i Altaba A, Jessell TM: Retinoic acid modifies the pattern of cell differentiation in the central nervous system of neurula stage Xenopus embryos. Development 1991, 112(4):945-958.

107. Chazaud C, Chambon P, Dolle P: Retinoic acid is required in the mouse embryo for left-right asymmetry determination and heart morphogenesis. Development 1999, 126(12):2589-2596.

108. Huang S, Ma J, Liu X, Zhang Y, Luo L: Retinoic acid signaling sequentially controls visceral and heart laterality in zebrafish. $J$ Biol Chem 286(32):28533-28543.

109. Vermot J, Gallego Llamas J, Fraulob V, Niederreither K, Chambon P, Dolle P: Retinoic acid controls the bilateral symmetry of somite formation in the mouse embryo. Science 2005, 308(5721):563-566.

110. Vermot J, Pourquie O: Retinoic acid coordinates somitogenesis and leftright patterning in vertebrate embryos. Nature 2005, 435(7039):215-220.

111. Anderson DJ: Lineages and transcription factors in the specification of vertebrate primary sensory neurons. Curr Opin Neurobiol 1999, 9(5):517-524

112. Ribes V, Stutzmann F, Bianchetti L, Guillemot F, Dolle P, Le Roux I: Combinatorial signalling controls Neurogenin2 expression at the onset of spinal neurogenesis. Dev Biol 2008, 321(2):470-481.

113. Coyle DE, Li J, Baccei M: Regional differentiation of retinoic acid-induced human pluripotent embryonic carcinoma stem cell neurons. PLoS One 2011, 6(1):e16174. 
114. Shan ZY, Liu F, Lei L, Li QM, Jin LH, Wu YS, Li X, Shen JL: Generation of dorsal spinal cord GABAergic neurons from mouse embryonic stem cells. Cell Reprogram 2011, 13(1):85-91.

115. Chen N, Napoli JL: All-trans-retinoic acid stimulates translation and induces spine formation in hippocampal neurons through a membraneassociated RARalpha. FASEB J 2008, 22(1):236-245.

116. Krumlauf R: Hox genes and pattern formation in the branchial region of the vertebrate head. Trends Genet 1993, 9(4):106-112.

117. Studer M, Lumsden A, Ariza-McNaughton L, Bradley A, Krumlauf R: Altered segmental identity and abnormal migration of motor neurons in mice lacking Hoxb-1. Nature 1996, 384(6610):630-634.

118. Marshall H, Nonchev S, Sham MH, Muchamore I, Lumsden A, Krumlauf R: Retinoic acid alters hindbrain Hox code and induces transformation of rhombomeres 2/3 into a 4/5 identity. Nature 1992, 360(6406):737-741.

119. Kessel M: Reversal of axonal pathways from rhombomere 3 correlates with extra Hox expression domains. Neuron 1993, 10(3):379-393.

120. Hill J, Clarke JD, Vargesson N, Jowett T, Holder N: Exogenous retinoic acid causes specific alterations in the development of the midbrain and hindbrain of the zebrafish embryo including positional respecification of the Mauthner neuron. Mech Dev 1995, 50(1):3-16.

121. Hernandez RE, Rikhof HA, Bachmann R, Moens CB: vhnf1 integrates global RA patterning and local FGF signals to direct posterior hindbrain development in zebrafish. Development 2004, 131(18):4511-4520.

122. Wiellette EL, Sive H: vhnf1 and Fgf signals synergize to specify rhombomere identity in the zebrafish hindbrain. Development 2003, 130(16):3821-3829.

123. Begemann G, Meyer A: Hindbrain patterning revisited: timing and effects of retinoic acid signalling. Bioessays 2001, 23(11):981-986.

124. Gavalas A: ArRAnging the hindbrain. Trends Neurosci 2002, 25(2):61-64.

125. Dupe $V$, Lumsden $A$ : Hindbrain patterning involves graded responses to retinoic acid signalling. Development 2001, 128(12):2199-2208.

126. Begemann G, Schilling TF, Rauch GJ, Geisler R, Ingham PW: The zebrafish neckless mutation reveals a requirement for raldh2 in mesodermal signals that pattern the hindbrain. Development 2001, 128(16):3081-3094.

127. Partanen J: FGF signalling pathways in development of the midbrain and anterior hindbrain. J Neurochem 2007, 101(5):1185-1193.

128. Emoto $Y$, Wada H, Okamoto H, Kudo A, Imai Y: Retinoic acid-metabolizing enzyme Cyp26a1 is essential for determining territories of hindbrain and spinal cord in zebrafish. Dev Biol 2005, 278(2):415-427.

129. Chen Y, Pan FC, Brandes N, Afelik S, Solter M, Pieler T: Retinoic acid signaling is essential for pancreas development and promotes endocrine at the expense of exocrine cell differentiation in Xenopus. Dev Biol 2004, 271(1):144-160.

130. Stafford D, Hornbruch A, Mueller PR, Prince VE: A conserved role for retinoid signaling in vertebrate pancreas development. Dev Genes Evol 2004, 214(9):432-441

131. Martin M, Gallego-Llamas J, Ribes V, Kedinger M, Niederreither $K_{1}$ Chambon P, Dolle P, Gradwohl G: Dorsal pancreas agenesis in retinoic acid-deficient Raldh2 mutant mice. Dev Biol 2005, 284(2):399-411.

132. Molotkov A, Molotkova N, Duester G: Retinoic acid generated by Raldh2 in mesoderm is required for mouse dorsal endodermal pancreas development. Dev Dyn 2005, 232(4):950-957.

133. Pan FC, Chen Y, Bayha E, Pieler T: Retinoic acid-mediated patterning of the pre-pancreatic endoderm in Xenopus operates via direct and indirect mechanisms. Mech Dev 2007, 124(7-8):518-531.

134. Bayha E, Jorgensen MC, Serup P, Grapin-Botton A: Retinoic acid signaling organizes endodermal organ specification along the entire anteroposterior axis. PLoS One 2009, 4(6):e5845.

135. Stafford D, Prince VE: Retinoic acid signaling is required for a critical early step in zebrafish pancreatic development. Curr Biol 2002, 12(14):1215-1220.

136. Stafford D, White RJ, Kinkel MD, Linville A, Schilling TF, Prince VE: Retinoids signal directly to zebrafish endoderm to specify insulin-expressing betacells. Development 2006, 133(5):949-956.

137. Dalgin G, Ward AB, Hao le T, Beattie CE, Nechiporuk A, Prince VE: Zebrafish $\mathrm{mnx} 1$ controls cell fate choice in the developing endocrine pancreas. Development 138(21):4597-4608.

138. Kinkel MD, Prince VE: On the diabetic menu: zebrafish as a model for pancreas development and function. Bioessays 2009, 31(2):139-152.
139. Kinkel MD, Eames SC, Alonzo MR, Prince VE: Cdx4 is required in the endoderm to localize the pancreas and limit beta-cell number. Development 2008, 135(5):919-929.

140. Ostrom M, Loffler KA, Edfalk S, Selander L, Dahl U, Ricordi C, Jeon J, CorreaMedina M, Diez J, Edlund H: Retinoic acid promotes the generation of pancreatic endocrine progenitor cells and their further differentiation into beta-cells. PLoS One 2008, 3(7):e2841

141. Tulachan SS, Doi R, Kawaguchi Y, Tsuji S, Nakajima S, Masui T, Koizumi M, Toyoda $E$, Mori $T$, Ito $D$, et al: All-trans retinoic acid induces differentiation of ducts and endocrine cells by mesenchymal/epithelial interactions in embryonic pancreas. Diabetes 2003, 52(1):76-84.

142. Shen CN, Marguerie A, Chien CY, Dickson C, Slack JM, Tosh D: All-trans retinoic acid suppresses exocrine differentiation and branching morphogenesis in the embryonic pancreas. Differentiation 2007, 75(1):62-74.

143. Moriya N, Komazaki S, Takahashi S, Yokota C, Asashima M: In vitro pancreas formation from Xenopus ectoderm treated with activin and retinoic acid. Dev Growth Differ 2000, 42(6):593-602.

144. Asashima M, Michiue T, Kurisaki A: Elucidation of the role of activin in organogenesis using a multiple organ induction system with amphibian and mouse undifferentiated cells in vitro. Dev Growth Differ 2008, 50(Suppl 1):S35-45.

145. Heine UI, Roberts AB, Munoz EF, Roche NS, Sporn MB: Effects of retinoid deficiency on the development of the heart and vascular system of the quail embryo. Virchows Arch B Cell Pathol Ind Mol Pathol 1985, 50(2):135-152.

146. Lin SC, Dolle P, Ryckebusch L, Noseda M, Zaffran S, Schneider MD, Niederreither K: Endogenous retinoic acid regulates cardiac progenitor differentiation. Proc Natl Acad Sci USA 2010, 107(20):9234-9239.

147. Sirbu IO, Zhao X, Duester G: Retinoic acid controls heart anteroposterior patterning by down-regulating IsI1 through the Fgf8 pathway. Dev Dyn 2008, 237(6):1627-1635.

148. Stachurska E, Loboda A, Niderla-Bielinska J, Szperl M, Juszynski M, Jozkowicz A, Dulak J, Ratajska A: Expression of cellular retinoic acidbinding protein I and II (CRABP I and II) in embryonic mouse hearts treated with retinoic acid. Acta Biochim Pol 2011, 58(1):19-29.

149. Keegan BR, Feldman $J$, Begemann G, Ingham PW, Yelon D: Retinoic acid signaling restricts the cardiac progenitor pool. Science 2005, 307(5707):247-249

150. Ryckebusch L, Wang Z, Bertrand N, Lin SC, Chi X, Schwartz R, Zaffran S, Niederreither K: Retinoic acid deficiency alters second heart field formation. Proc Natl Acad Sci USA 2008, 105(8):2913-2918.

151. Mathew LK, Sengupta S, Franzosa JA, Perry J, La Du J, Andreasen EA, Tanguay RL: Comparative expression profiling reveals an essential role for raldh2 in epimorphic regeneration. J Biol Chem 2009, 284(48):33642-33653.

152. Kikuchi K, Holdway JE, Major RJ, Blum N, Dahn RD, Begemann G, Poss KD: Retinoic acid production by endocardium and epicardium is an injury response essential for zebrafish heart regeneration. Dev Cell 20(3):397-404

153. Serluca FC, Fishman MC: Pre-pattern in the pronephric kidney field of zebrafish. Development 2001, 128(12):2233-2241.

154. Cartry J, Nichane M, Ribes V, Colas A, Riou JF, Pieler T, Dolle P, Bellefroid EJ, Umbhauer M: Retinoic acid signalling is required for specification of pronephric cell fate. Dev Biol 2006, 299(1):35-51.

155. Mendelsohn C, Lohnes D, Decimo D, Lufkin T, LeMeur M, Chambon P, Mark M: Function of the retinoic acid receptors (RARs) during development (II). Multiple abnormalities at various stages of organogenesis in RAR double mutants. Development 1994, 120(10):2749-2771

156. Carroll TJ, Vize PD: Synergism between Pax-8 and lim-1 in embryonic kidney development. Dev Biol 1999, 214(1):46-59.

157. Lee SJ, Kim S, Choi SC, Han JK: XPteg (Xenopus proximal tubulesexpressed gene) is essential for pronephric mesoderm specification and tubulogenesis. Mech Dev 2010, 127(1-2):49-61.

158. Bollig F, Perner B, Besenbeck B, Kothe S, Ebert C, Taudien S, Englert C: A highly conserved retinoic acid responsive element controls wt1a expression in the zebrafish pronephros. Development 2009, 136(17):2883-2892. 
159. Perner B, Englert C, Bollig F: The Wilms tumor genes wt1a and wt $1 \mathrm{~b}$ control different steps during formation of the zebrafish pronephros. Dev Biol 2007, 309(1):87-96.

160. Osafune K, Nishinakamura R, Komazaki S, Asashima M: In vitro induction of the pronephric duct in Xenopus explants. Dev Growth Differ 2002, 44(2):161-167.

161. Wingert RA, Selleck R, Yu J, Song HD, Chen Z, Song A, Zhou Y, Thisse B, Thisse C, McMahon AP, et al: The $c d x$ genes and retinoic acid control the positioning and segmentation of the zebrafish pronephros. PLoS Genet 2007, 3(10):1922-1938.

162. Rosselot C, Spraggon L, Chia I, Batourina E, Riccio P, Lu B, Niederreither K, Dolle P, Duester G, Chambon P, et al: Non-cell-autonomous retinoid signaling is crucial for renal development. Development 137(2):283-292.

163. Desai TJ, Malpel S, Flentke GR, Smith SM, Cardoso WV: Retinoic acid selectively regulates Fgf10 expression and maintains cell identity in the prospective lung field of the developing foregut. Dev Biol 2004, 273(2):402-415.

164. Desai TJ, Chen F, Lu J, Qian J, Niederreither K, Dolle P, Chambon P, Cardoso WV: Distinct roles for retinoic acid receptors alpha and beta in early lung morphogenesis. Dev Biol 2006, 291(1):12-24.

165. Chen F, Cao Y, Qian J, Shao F, Niederreither K, Cardoso WV: A retinoic aciddependent network in the foregut controls formation of the mouse lung primordium. J Clin Invest 120(6):2040-2048.

166. Malpel S, Mendelsohn C, Cardoso WV: Regulation of retinoic acid signaling during lung morphogenesis. Development 2000, 127(14):3057-3067.

167. Shiotsugu J, Katsuyama Y, Arima K, Baxter A, Koide T, Song J, Chandraratna RA, Blumberg B: Multiple points of interaction between retinoic acid and FGF signaling during embryonic axis formation. Development 2004, 131(11):2653-2667.

168. Ho L, Mercola M, Gudas L: Xenopus laevis cellular retinoic acid-binding protein: temporal and spatial expression pattern during early embryogenesis. Mech Dev 1994, 47(1):53-64.

169. Kam RK, Chen Y, Chan SO, Chan WY, Dawid IB, Zhao H: Developmental expression of Xenopus short-chain dehydrogenase/reductase 3. Int J Dev Biol 2010, 54(8-9):1355-1360.

doi:10.1186/2045-3701-2-11

Cite this article as: Kam et al:: Retinoic acid synthesis and functions in early embryonic development. Cell \& Bioscience 2012 2:11.

\section{Submit your next manuscript to BioMed Central and take full advantage of:}

- Convenient online submission

- Thorough peer review

- No space constraints or color figure charges

- Immediate publication on acceptance

- Inclusion in PubMed, CAS, Scopus and Google Scholar

- Research which is freely available for redistribution

Submit your manuscript at www.biomedcentral.com/submit
Biomed Central 